\title{
WYKAZ PRAC DYPLOMOWYCH Z ANTYKU CHRZEŚCIJAŃSKIEGO UKOŃCZONYCH W NIEKTÓRYCH POLSKICH OŚRODKACH NAUKOWYCH W 2001 ROKU
}

\section{KATOLICKI UNIWERSYTET LUBELSKI}

\section{A. WYDZIAŁ TEOLOGICZNY}

Kolokwia habilitacyjne

1. O. dr Nieścior Leon OMI, Asceza chrześcijańska i filozofia w pismach Nila z Ancyry, Poznań 2001. Kolokwium habilitacyjne 25 VI 2001 r.; recenzenci: ks. prof. dr hab. B. Częsz (UAM), ks. prof. dr hab. F. Drączkowski (KUL), prof. dr hab. J. Wojtczak (UW). Tytuł: doktor habilitowany nauk teologicznych w zakresie patrologii.

$$
\text { Prace doktorskie }
$$

1. Ks. Bartuch Stefan, Model życia chrześcijańskiego w świetle pism ascetycznych św. Bazylego Wielkiego. Obrona 6 XII 2001; promotor - ks. prof. dr hab. J. Misiurek, recenzenci: ks. prof. dr hab. F. Drączkowski (KUL), ks. prof. dr hab. S. Urbański (UKSW).

2. Ks. Jaśkiewicz Grzegorz, Keryks - kerygma w mowach Grzegorza z Nazjanzu. Obrona 20 VI 2001; promotor - ks. prof. dr hab. F. Drączkowski; recenzenci: ks. prof. dr hab. J. Pałucki (KUL), ks. prof. dr hab. W. Pazera (UKSW).

3. Ks. Ratko Stanisław, Rola walki duchowej w życiu pustelniczym według św. Antoniego Pustelnika. Obrona 16 V 2001; promotor - ks. prof. dr hab. W. Słomka; recenzenci: ks. prof. dr hab. M. Chmielewski (KUL), ks. prof. dr hab. S. Urbański (UKSW).

\section{Prace magisterskie}

1. Dąbrowski Jerzy, „Pożadliwość” w sporze św. Augustyna z Julianem z. Eklanu (prom. ks. prof. dr hab. P. Drączkowski).

2. Dułak Tadeusz, Obraz człowieka w dialogach filozoficznych św. Augustyna (prom. ks. prof. dr hab. A. Eckmann). 
3. Dwernytska Jarosława, Duch Święty w Liturgii św. Jana Chryzostoma (prom. ks. dr Z. Krzyszowski).

4. Fryc Tomasz, Aretologia św. Grzegorza Wielkiego w świetle „Homilii na Ewangelie" (prom. ks. prof. dr hab. F. Drączkowski).

5. Gałązka Adam, Obraz Boga prawdziwego w świetle „Quaestiones in Heptateuchum" św. Augustyna (prom. ks. prof. dr hab. F. Drączkowski).

6. Gierko Mirosław, Lex Dei w „Enarrationes in Psalmos” św. Augustyna (prom. ks. prof. dr hab. F. Drączkowski),

7. Gościński Jarosław, Nauka Ewagriusza z Pontu o modlitwie umysłu jako fundamencie Modlitwy Jezusowej (prom. ks. prof. dr hab. J. Misiurek).

8. Jushewysch Halyna, Nawrócenie w nauczaniu św. Jana Chryzostoma (prom. ks. dr Z. Krzyszowski).

9. Kravets Roman, Pochodzenie Ducha Świętego w nauczaniu św. Jana Damasceńskiego (prom. ks. prof. dr hab. K. Góźdź).

10. Laniecki Marcin, „Pożadliwość” w świetle pism św. Augustyna ze szczególnym uwzględnieniem „Enarrationes in Psalmos” (prom. ks. prof. dr hab. A. Eckmann).

11. Łazar Władimir, Postać św. Jana Chrzciciela w Komentarzu Orygenesa do Ewangelii św. Łukasza ( prom. ks. prof. dr hab. A. Paciorek).

12. Łepek Piotr, Oskarżenie chrześcijan i ich odparcie w świetle pism apologetycznych Tertuliana (prom. ks. prof. dr hab. F. Drączkowski).

13. Sidor Dariusz, Maryja w apokryfach Nowego Testamentu (prom. ks. prof. dr hab. J. Pałucki).

14. Stefański Leszek, Miłość-agape w mowach Grzegorza Teologa (prom. prof. dr hab. F. Drączkowski).

15. Szwal Jan, Odmienności występujące w czterech ewangeliach w świetle „De consensu evangelistarum” św. Augustyna (prom. ks. prof. dr hab. F. Drączkowski).

16. Topolski Tadeusz, Imiona Maryi w łacińskich przekazach patrystycznych (prom. ks. prof. dr hab. F. Drączkowski).

17. Wierzbicki Wojciech, „Caritas” - „dilectio” w wykładzie św. Ambrożego do Ewangelii według św. Łukasza (prom. ks. prof. dr hab. F. Drączkowski).

B. WYDZIAŁ HUMANISTYCZNY

\section{Instytut Filologii Klasycznej - Katedra Literatury Wczesnochrześcijańskiej}

$$
\text { Prace doktorskie }
$$

1. Ks. Burczak Krzysztof, Figury retoryczne i tropy w Psalmach na podstawie „Expositio Psalmorum” Kasjodora. Obrona 20 V 2001; promotor - ks. prof. dr hab. H. Wójtowicz: recenzenci: prof. dr hab. J. Wojtczak (UW), ks. dr hab. S. Longosz (KUL). 
Prace magisterskie

1. Jaśkiewicz Grzegorz, Motyw radości w „Enarrationes in Psalmos” św. Augustyna (prom. ks. prof. dr hab. A. Eckmann).

\section{Instytut Historii Sztuki - Katedra Sztuki Starożytnej i Wczesnochrześcijańskiej}

Prace magisterskie

1. Radzka Anna, Clonmacnois - Historia i rozkwit ośrodka artystycznego od momentu powstania do końca XII wieku (prom. prof. dr hab. B. Iwaszkiewicz-Wronikowska).

C. WYDZIAŁ PRAWA, PRAWA KANONICZNEGO I ADMINISTRACJI

\section{Sekcja Prawa Kanonicznego}

Prace magisterskie

1. Ks. Burianek Jarosław, Rozwój historyczny podstawowych regut instytutów zakonnych (prom. ks. prof. dr hab. A. Dębiński).

2. Ks. Jóźwiak Stanisław, Problematyka prawna w „De civitate Dei” św. Augustyna (prom. ks. prof. dr hab. A. Dębiński).

3. Sokół Beata, Kara ekskomuniki w ustawodawstwie kościelnym. Studium historyczno-prawne (prom. ks. dr Z. Podlecki).

\section{UNIWERSYTET KARD. STEFANA WYSZYŃSKIEGO W WARSZAWIE}

\section{A. WYDZIAŁ KOŚCIELNYCH NAUK HISTORYCZNYCH I SPOŁECZNYCH}

$$
\text { Prace magisterskie }
$$

1. Bożyk Marlena, „Antygona” Sofoklesa $i$ „Komentarz do Pieśni nad Pieśniami” Orygenesa jako dramat antyczny (prom. ks. prof. dr hab. T. Kołosowski).

2. Połowienia Magdalena, Niewolnictwo w świetle pisma „De gubernatione Dei" Salwiana z Marsylii (prom. ks. prof. dr hab. T. Kołosowski).

3. Ks. Skóra Wojciech, Recepcja myśli patrystycznej w pneumatologii Henry Edwarda Manninga (ks. prof. dr hab. J. Naumowicz).

4. Szymański Gabriel, Problem choroby w wybranych pismach św. Augustyna (prom. ks. dr hab. T. Kołosowski).

5. Zakrzewska Agnieszka, „Peregrinatio” u mnichów iroszkockich w świetle dziet Kolumbana i Jonasza z Bobbio (prom. ks. dr hab. T. Kołosowski). 


\section{PAPIESKA AKADEMIA TEOLOGICZNA W KRAKOWIE}

\section{A. WYDZIAE TEOLOGICZNY W KRAKOWIE}

\section{Kolokwia habilitacyjne}

1. Ks. dr Jan Słomka, Pokarm i ofiara. Refleksja eucharystyczna wczesnych Ojców greckich, Łódź 2000. Kolokwium habilitacyjne 18 VI 2001; recenzenci: ks. prof. dr hab. E. Staniek (PAT), ks. prof. dr hab. W. Myszor (UKSW), ks. prof. dr hab. H. Pietras (Ignatianum, Kraków); tytuł: doktor habilitowany nauk teologicznych w zakresie patrologii.

\section{Prace licencjackie}

1. Kaczmarek Sylwia, Eklezjalny wymiar pokuty w „Listach” Bazylego Wielkiego (promotor ks. prof. dr hab. Edward Staniek).

\section{Prace magisterskie}

1. Fundak Mario OSPPE, „Laudo nuptias, laudo coniugium, sed quia mihi virgines generant". Wyższość dziewictwa względem matżeństwa $w$ listach św. Hieronima (prom. ks. dr A. Bandura CM).

2. Golian Józef, Warunki i formy modlitwy u Ojców Pustyni według „Historia Lausiaca" Palladiusza (prom. ks. prof. dr hab. H. Pietras SJ).

3. Jarząbek Bożena, Życie codzienne w Antiochii na podstawie „Homilii na List św. Pawła do Rzymian” św. Jana Chryzostoma (prom. ks. dr Arkadiusz Baron)

4. Mońko Mikołaj, Obraz i podobieństwo. Studium antropologiczne dzieła „O stworzeniu człowieka” św. Grzegorza z Nyssy (prom. ks. dr Jan Żelazny).

\section{B. ZAMIEJSCOWY WYDZIAE TEOLOGICZNY W TARNOWIE}

\section{Prace magisterskie}

1. Ks. Bonarek Kazimierz, Grzegorz Wielki obrońca sprawiedliwości (prom. ks. dr S. Sojka).

2. Kozub Halina, Ideat wychowania w nauczaniu Klemensa Aleksandryjskiego (prom. ks. dr S. Sojka).

3. Krupa Zofia, Modlitwa wedtug Orygenesa (prom. ks. dr S. Sojka).

4. Owczarska Maria, Tożsamość chrześcijanina w świetle „Apologetyku” Tertuliana (prom. ks. dr hab. A. Żurek).

5. Stolarczyk Renata, Sny i wizje w najstarszych „, Męczeństwach”. Zasadnicze linie interpretacyjne (prom. ks. dr hab. A. Żurek).

6. Ks. Zapiór Marian, Kapłan jako pasterz w pismach Grzegorza Wielkiego (prom. ks. dr S. Sojka). 


\title{
V. UNIWERSYTET ADAMA MICKIEWICZA W POZNANIU (UAM)
}

\section{A. WYDZIAE TEOLOGICZNY}

\author{
Prace doktorskie
}

1. Kotkowska Elżbieta, Perspektywa historio-zbawcza człowieka i kosmosu według św. Grzegorza z Nyssy. Obrona 31 I 2001; promotor - ks. prof. dr hab. B. Częsz; recenzenci: ks. prof. dr hab. H. Pietras (Ignatianum, Kraków), ks. prof. dr hab. T. Węcławski (UAM).

\section{Prace magisterskie}

1. Borowczyk Małgorzata, Zagrożenia dla Kościoła w świetle listów św. Bazylego (prom. ks. dr P. Wygralak).

2. Dudek Piotr, Usprawiedliwienie z wiary i uczynków w Orygenesowym „Komentarzu do Listu do Rzymian” ( prom. ks. dr hab. L. Nieścior).

3. Pieprzyk Iwona, Walka mnicha ze złymi duchami na podstawie „Zywota św. Antoniego” św. Atanazego oraz „Żywotów mnichów Pawła, Hilariona i Malchusa” sw. Hieronima (prom. ks. dr P. Wygralak).

4. Rosińska Wanda, Miłość Boga i bliźniego droga do doskonatości chrześcijańskiej w wybranych dziełach św. Maksyma Wyznawcy (prom. ks. dr P. Wygralak).

5. Sobierajski Przemysław, Krytyka pelagianizmu w listach św. Augustyna (prom. ks. dr P. Wygralak).

6. Szczutkowska Ewa, Rady ewangeliczne jako fundament zycia duchowego dziewicy w ujęciu św. Ambrożego (prom. ks. dr P. Wygralak).

7. Świtalska Agnieszka, Pochwała dziewictwa w świetle pierwszych pism greckich o dziewictwie (prom. ks. dr P. Wygralak).

8. Winkler Wanda, Postawa chrześcijanina wobec choroby $i$ śmierci $w$ listach św. Hieronima (prom. ks. dr P. Wygralak).

B. INSTYTUT HISTORII UAM

$$
\text { Prace magisterskie }
$$

1. Tomaszewska Ewa, Biskup w świetle pism św. Augustyna (prom. prof. dr hab. L. Mrozewicz).

C. WYŻSZE SEMINARIUM DUCHOWNE W GNIEŹNIE (agregowane do UAM)

$$
\text { Prace magisterskie }
$$

1. S. Berełkowska Bernadetta, Organizacja życia w klasztorze żeńskim na podstawie „Reguty dla dziewic” św. Cezarego z Arles (prom. ks. dr B. Czyżewski). 
2. S. Glapa Grażyna, Wskazania ascetyczne dla dziewic w „Regule” św. Leandra (prom. ks. dr B. Czyżewski).

3. Janke Małgorzata, Chrystocentryczna interpretacja tekstów biblijnych w „Dialogu z Żydem Tryfonem” św. Justyna (prom. ks. dr B. Czyżewski).

4. Lewicka Łucja, Alegoryczna interpretacja Oblubieńca i Oblubienicy w „Komentarzu do Pieśni nad Pieśniami” Orygenesa (prom. ks. dr B. Czyżewski).

5. Łukowski Piotr, Kontemplacja tajemnicy Chrystusa i Jego Kościoła w kazaniach i homiliach św. Chromacjusza, bpa Akwilei (prom. ks. dr L. Gładyszewski).

6. Niedziela Krystyna, Zło społeczne w ujęciu św. Bazylego Wielkiego (prom. ks. dr B. Czyżewski).

7. Nowakowska Agnieszka, Biblijne uzasadnienie Bóstwa Chrystusa w traktacie „O Wcieleniu Stowa” św. Atanazego Aleksandryjskiego (prom. ks. dr B. Czyżewski).

8. Jarosław Orczykowski, Polemika z przeciwnikami politycznymi i religijnymi w „Apologii do Konstancjusza” św. Atanazego Aleksandryjskiego (prom. ks. dr B. Czyżewski).

9. Szajda Małgorzata, Teologia obrzędów chrzcielnych $w$ „Katechezach mistagogicznych" św. Cyryla Jerozolimskiego.

10. Szczepańska Marzena, Doskonalenie siebie jako zadanie chrześcijanina na podstawie mów i kazań św. Grzegorza z Nyssy (prom. ks. dr B. Czyżewski).

11. Tomaszewski Hubert, Podstawy teologiczne kultu obrazów w mowach apologetycznych św. Jana Damasceńskiego (prom. ks. dr B. Czyżewski).

D. WYŻSZE SEMINARIUM DUCHOWNE W KOSZALINIE (agregowane do UAM)

\section{Prace magisterskie}

1. Kowal Sebastian, Drogi do zjednoczenia z Bogiem w interpretacji PseudoDionizego Areopagity (prom. ks. dr J. Chęciński).

2. Kwieciński Norbert, Jeden Duch - wiele działań. Interpretacja 1 Kor 12, 1 11, w „Katechezach” Cyryla Jerozolimskiego (prom. ks. dr J. Chęciński).

\section{UNIWERSYTET OPOLSKI}

\section{A. WYDZIAE TEOLOGICZNY}

Katedra Historii Kościoła i Patrologii - kierownik ks. dr N. Widok

$$
\text { Prace magisterskie }
$$

1. Ciomek Jerzy, Nauka św. Augustyna o nieśmiertelności duszy ludzkiej $w$ „Dialogach filozoficznych” $i$ w traktacie „O Trójcy Świętej”. 
2. Kirklo-Rusek Elwira, Nauka św. Augustyna o małzeństwie w traktacie „De bono coniugali".

3. Kołodziejczak Elżbieta, Działalność charytatywna Bazylego Wielkiego.

4. Latos Barbara, Chrześcijańskie zasady życia kobiet w świetle „Listów” św. Hieronima

5. Mańka Krzysztof, Wizja pokoju w „Państwie Bożym” św. Augustyna

6. Mitas Zenon, Łaska w nauczaniu św. Augustyna w traktatach o łasce.

7. Opaliński Mariusz, Przyjaźń w życiu św. Grzegorza z Nazjanzu.

\section{PAPIESKI WYDZIAE TEOLOGICZNY W WARSZAWIE - SEKCJA ŚW. JANA CHRZCICIELA}

Kolokwia habilitacyjne

1. Ks. dr Waldemar Turek, Grzech przeciw Duchowi Świętemu w tradycji patrystycznej, Kraków 2000; Kolokwium habilitacyjne: 18 I 2001; recenzenci: ks. prof. dr hab. J. Kulisz (UKSW), ks. prof. dr hab. M. Starowieyski (UW), ks. prof. dr hab. H. Pietras (Ignatianum, Kraków); tytuł: doktor habilitowany nauk teologicznych w zakresie patrologii.

$$
\text { Prace magisterskie }
$$

1. S. Biłas Miriam Katarzyna, Post w nauczaniu św. Bazylego Wielkiego (prom. ks. dr hab. J. Naumowicz).

2. Dembiński Eugeniusz, Motywy autobiograficzne w mowach i poematach św. Grzegorza z Nazjanzu (prom. ks. dr hab. J. Naumowicz).

3. Marczak Edyta, Zasady życia duchowego według „Apoftegmatów” Ojców Pustyni (prom. ks. dr hab. J. Naumowicz).

\section{PAPIESKI WYDZIAt TEOLOGICZNY WE WROCŁAWIU}

$$
\text { Prace licencjackie }
$$

1. Gwiździel M., Nauka św. Ambrożego o modlitwie.

$$
\text { Prace magisterskie }
$$

1. Debski M., Pustynia miejscem doskonalenia wewnętrznego w świetle wczesnego monastycyzmu egipskiego.

2. Drab W., Pascha Izraela jako pascha chrześcijańska. Wykorzystanie Starego Testamentu w katechezie chrzcielnej Orygenesa.

3. Lota Adam, Prześladowanie chrześcijan pierwszych wieków ze szczególnym uwzględnieniem gminy rzymskiej do Edyktu Mediolańskiego w 315 roku (prom. ks. prof. dr hab. J. Swastek). 
4. Mikoluk Anna, Starożytne źródła $i$ współczesne realia monastycyzmu miejskiego na przykładzie Jerozolimskich Wspólnot Monastycznych (prom. ks. dr hab. A. Siemieniewski).

5. Rutkowski Krzysztof, Stosunek Marka Aureliusza do chrześcijaństwa (prom. ks. prof. dr hab. I. Dec).

6. Semenowicz Dorota, Prześladowanie i męczeństwo chrześcijan w świetle Apokalipsy św. Jana (prom. ks. dr H. Lempa).

7. Sienkiewicz H., Nauka o Kościele w ujęciu Orygenesa ze szczególnym uwzględnieniem jego traktatu „De principiis”.

8. Szmul Renata, Pojednanie grzesznika w Kościele starożytnym (prom. ks. prof. dr hab. A. Młotek).

\section{WYŻSZA SZKOŁA FILOZOFICZNO-PEDAGOGICZNA „IGNATIANUM” W KRAKOWIE}

\section{A. WYDZIAE PEDAGOGICZNY}

$$
\text { Prace magisterskie }
$$

1. Janotikova Jana, Boża pomoc w walce ze ztem na podstawie homilii Orygenesa do Księgi Wyjścia (prom. ks. prof. dr hab. H. Pietras).

2. Trofimowa Julia, Symbolika świątyni wczesnochrześcijańskiej (prom. ks. prof. dr hab. H. Pietras).

\section{WYŻSZE SEMINARIUM DUCHOWNE W KIELCACH}

\section{Prace magisterskie (bronione na PAT)}

1. Jankoski Andrzej, Św. Wawrzyniec w tacińskiej literaturze wczesnochrześcijańskiej (prom. ks. dr T. Gacia).

2. Majka Jerzy, Świętość małżeństwa w dziełach św. Ambrożego (prom. ks. dr K. Gurda).

3. Olejarczyk Michał, Hymny św. Ambrożego: geneza, źródła inspiracji, teologia (prom. ks. dr K. Gurda).

\section{WYŻSZE SEMINARIUM DUCHOWNE W LODZI}

Prace magisterskie (bronione na UKSW)

1. Dąbrowski Artur, Chrystologiczne i trynitarne interpretacje tekstów biblijnych u św. Ambrożego i św. Augustyna (prom. ks. dr hab. J. Słomka).

2. S. Fraszczak Ewa CSSF, Cnoty kardynalne w ujęciu św. Ambrożego. Studium traktatu „Obowiazki duchownych” (prom. ks. dr hab. J. Słomka).

3. Gajzler Beata, Modlitwa według św. Cypriana (prom. ks. dr hab. J. Słomka). 
4. Piasecki Józef, Historia pojęcia apokatastazy w starożytności chrześcijańskiej (prom. ks. dr hab. J. Słomka).

5. Pietrzak Aneta, Program wychowawczy św. Jana Chryzostoma na tle ówczesnych tradycji pogańskich (prom. ks. dr hab. J. Słomka).

6. Steżalska Elżbieta, Postać Jezusa w polemice Orygenesa z Celsusem (prom. ks. dr hab. J. Słomka).

7. Świeszczakowska Aneta, Modlitwa w apoftegmatech Ojców Pustyni (prom. ks. dr hab. J. Słomka).

8. Zwoliński Tomasz, Polemika św. Augustyna z manichejska koncepcją dobra i zła (prom. ks. dr hab. J. Słomka).

\section{WYŻSZE SEMINARIUM DUCHOWNE W PELPLINIE}

Prace magisterskie (bronione w KUL)

1. Adamski Andrzej, Nauka o aniołach w Orygenesowych Homiliach o Księdze Liczb (prom. ks. dr D. Drążek).

2. Czecholiński Marcin, Św. Marcin z Tours jako człowiek wiary i cudotwórca w „Żywocie”, „Listach” $i$,Dialogach” Sulpicjusza Sewera (prom. ks. dr D. Drążek).

3. Trapkowski Wojciech, Inspiracje augustyńskie w nauce Katechizmu Kościoła Katolickiego o Dziesięciu Przykazaniach Bożych (prom. ks. dr D. Drążek).

4. Zimny Tomasz, Nauka o grzechu w świetle augustyńskich „Homilii na Ewangelię św. Jana” (prom. ks. dr D. Drążek).

\section{WYŻSZE SEMINARIUM DUCHOWNE W RADOMIU}

$$
\text { Prace magisterskie (bronione w KUL) }
$$

1. Kowalska Joanna, Mitość Boga w dziełach św. Maksyma Wyznawcy (prom. ks. dr P. Turzyński).

2. Kruk Barbara, Miłość w apoftegmatach Ojców Pustyni (prom. ks. dr M. Korczyński).

3. Lutka Alicja, Zagadnienie śmierci w „Wyznaniach” św. Augustyna (prom. ks. dr P. Turzyński).

4. Murawska Elżbieta, Kosmos anielski jako idealny świat stworzony u Pseudo-Dionizego Areopagity (prom. ks. dr M. Korczyński).

\section{WYŻSZE SEMINARIUM DUCHOWNE WE WŁOCŁAWKU}

$$
\text { Prace magisterskie (bronione w KUL) }
$$

1. Dąbrowski Maciej, Temat krzyża w życiu chrześcijan według świadectw I-III wieku (prom. ks. dr T. Kaczmarek). 
2. Przybysz Józef, Chrześcijanin na modlitwie według świadectw trzech pierwszych wieków (prom. ks. dr T. Kaczmarek).

zebrał i opracował

ks. Stanisław Longosz - Lublin, KUL 